\title{
La cárcel física y mental en la narrativa de José Revueltas
}

\author{
Physical and mental prison \\ in the narrative of José Revueltas
}

\author{
ELÍAS FUENTES GUILLÉN \\ Universidad Nacional Autónoma de México
}

Recibido: 03-12-2018Ａceptado: 15-12-2018

\begin{abstract}
RESUMEN
El problema de la enajenación del ser humano es una constante en la obra teórica y narrativa de José Revueltas. El hecho de que el tema carcelario aparezca con frecuencia en sus relatos y novelas, en algunos de los cuales la cárcel deviene un personaje más, obedece precisamente a su interés en dicho problema. Como aquí se muestra, Revueltas no sólo buscaba exponer y analizar la enajenación humana, sino a la vez explorar posibles vías de liberación. De ahí que, mientras que en sus primeros trabajos se centró en el sistema penitenciario, gradualmente pasó a abordar en ellos el encierro en el espacio público y en la propia conciencia.
\end{abstract}

\section{PALABRAS CLAVE \\ JOSÉ REVUELTAS, CÁRCEL MENTAL, CÁRCEL FÍSICA, ENAJENACIÓN, CONCIENCIA}

\begin{abstract}
The problem of the alienation of the human being was central in the theoretical and narrative works of José Revueltas. Indeed, it is because of his interest in this problem that prison appears frequently in his short stories and novels, even as one more character. As we show here, Revueltas not only intended to show and study the human alienation, but at the same time he sought to explore possible ways of liberation. Hence, while in his early work he focused on the
\end{abstract}


penitentiary system, eventually he went on to focus on the confinement within the public space and consciousness.

KEYWORDS

JOSÉ REVUELTAS, MENTAL PRISON, PHYSICAL PRISON, ALIENATION

Le rêve de l'Etat, c'est d'être seul, le rêve des individus, c'est d'être deux. Jean-Luc Godard

\section{INTRODUCCIÓN}

EN LA OBRA DE José ReVUeltas (1914-1976), escritor y militante político mexicano, la cárcel actúa como un personaje más. Desde sus primeros relatos hasta los últimos, Revueltas examina la prisión y lo que ocurre en ella como un medio para comprender a las sociedades y a los seres humanos. Miembro desde muy joven de las juventudes comunistas, fue detenido por primera vez cuando aún era menor de edad y, a principios de la década de 1930, fue enviado por primera vez a las Islas Marías, donde el gobierno mexicano estableció desde principios del siglo XX una colonia penitenciaria. Como él mismo dijo años después, la experiencia en la cárcel le mostró «las relaciones humanas en su desnudez más completa, sin convenciones de ninguna especie» (Ruiz Abreu, 1993: 74).

La situación de los comunistas en México, sin embargo, cambió en la segunda mitad de la década de 1930 y algunas de sus demandas pasaron a ser consideradas constitutivas de la idea del Estado nacional. Como consecuencia, el Partido Comunista Mexicano (PCM) dejó de ser considerado ilegal y el gobierno, entre otras cosas, promovió la formación del Comité Nacional de Defensa Proletaria y más tarde la creación de la Confederación de Trabajadores de México (cf. Meyer, 1976). No obstante, el gobierno no siempre gozó del apoyo del PCM, como ocurrió cuando, en 1937, otorgó un permiso a Trotsky, lo cual fue abiertamente rechazado por el PCM dado que la política del partido era en ese entonces «unidad a toda costa» y aquél aparecía, desde Moscú, como un traidor (cf. Carr, 2000: 61-62).

Los primeros folletos y artículos de Revueltas son evidencia del tono acrítico y proselitista que entonces imperaba entre los militantes comunistas mexicanos (cf. Revueltas, 1984). ${ }^{1}$ De manera similar, sus primeras narraciones suelen exaltar el movimiento revolucionario y situar a los personajes comunistas como mártires de la lucha social (cf. 1981). Sin embargo, así como con el paso

1 En adelante, cuando se trate de una obra de José Revueltas sólo se indicará el año y, en su caso, la página citada, mientras que en las referencias a las obras de otras personas sí se indicará el apellido de las mismas. 
del tiempo la voz narradora en su obra se tornó cada vez más crítica respecto al dogmatismo partidista, el análisis «revueltiano» de la cárcel y de su ejercicio de poder sobre la conciencia se volvió a su vez cada vez más sofisticado. Como se mostrará aquí, entre la cárcel presentada en Los muros de agua (su primera novela publicada) y aquella presentada en El apando (su última novela) o en «El reojo del yo» (uno de sus últimos relatos publicados), medió el desarrollo de técnicas narrativas que le permitieran dar cuenta del sufrimiento y la enajenación de los presos.

\section{EL SISTEMA PENITENCIARIO}

En el prólogo a la segunda edición de 1961 de Los muros de agua, José Revueltas explicó que dicho trabajo representaba una «tentativa de lo que consider[aba] [un] realismo materialista y dialéctico», que contraponía al realismo socialista «de quienes se somet[ían] servilmente a los hechos como ante la cosa sagrada» (1978B: 20). Como apunta Álvaro Ruiz Abreu, el panorama literario mexicano de entonces estaba «caracterizado por la novela indigenista, la de la Revolución mexicana [...]; el realismo socialista o lo que en México se llamó ‘novela proletaria', y el relato costumbrista» (Ruiz Abreu, 1993: 145). Así, pese a que dicha novela compartía elementos de semejante realismo socialista y, sobretodo, de ese naciente género que James Irby denominara de «prisión política» (Irby, 1956), el proyecto de Revueltas buscaba mostrar -y coincidir con- el movimiento interno de la realidad material, en vez de reflejarla directamente.

Para empezar, el título de esa novela alude explícitamente a la subversión del océano Pacífico como límite natural de la Isla María Madre, convertido aquel en muro de la prisión que esta última albergaba. No es gratuito, por ende, que la persona narradora afirme que aquella, en tanto cárcel, era «a lo más, una idea, un concepto, nunca un lugar situado en el tiempo y en el espacio» (1941: 24). Aún más, como señala Javier Durán, ante la asunción de «la imposibilidad de lograr una liberación física» en semejante prisión, «[1]a evocación del pasado se convierte en el eje para sobrevivir el presente» (Durán, 2002: 158), esto es, el encierro, por parte de los presos; un presente que debido a ello es descrito por la persona narradora en términos espaciales, a saber, como «un cerro ancho, semicónico, sujeto a variaciones» (1941: 69), equiparándolo con la isla y reafirmando así el carácter central de ésta.

Precisamente, el grueso de la narración se construye a partir de dicho espacio, ya sea por acontecimientos presentes o remembranzas, si bien ella abarca desde la aprehensión y el traslado de cinco comunistas a la Isla María Madre, hasta el quiebre de estos y su resignación al «común destino de dolor, de sufrimiento y de voluntad callada para aguardar la alegría» (1941: 206). Hasta aproximadamente mediados de la década de 1960, este compromiso ideológico de los comunistas aún en los momentos de mayor desesperanza constituyó de 
hecho una diferencia resaltada en la narrativa de Revueltas respecto a los perseguidos y delincuentes comunes, entre quienes «no existía la menor solidaridad» y a quienes la persona narradora describe como «animal[es] de egoísmo» (1941: 136). En El luto humano (1943), por ejemplo, Natividad, un líder comunista que es presentado más bien como un «misionero» (Ruiz Abreu, 1993: 164), es contrapuesto a Adán, un pistolero a sueldo que responde a lo que Michel Foucault denomina «delincuencia útil» (Foucault, 1976: 284), cobijada y perpetuada en la legalidad del sistema (cf. 1980A). Mientras que en Los días terrenales (1949), Gregorio Saldívar, quien representa a la parte crítica y la esperanza del PCM, es contrapuesto a Fidel, el «cura rojo» que representa a la militancia dogmática y, por ende, a los comunistas que cabría considerar comunes (cf. Blanco, 1985: 13; Ruiz Abreu, 1993: 235).

Ahora bien, Revueltas sostiene que la animalización de los presos comunes, producida y perpetuada por la prisión y las jerarquías que se establecen en ella, es a su vez un reflejo de lo que ocurre extramuros en el sistema social que engendra dicha institución. Como dice Eugenia Revueltas, para José Revueltas la cárcel «no sólo es un cuerpo enfermo, [sino que] es un compendio, una condensación de las sociedades» (Eugenia Revueltas, 1985: 56). Así, su novela En algún valle de lágrimas (1957) culmina con la sentencia de un vagabundo, otrora director de una escuela, que justo alude a ello: «Todos estamos presos -dijo con la mirada baja-. Compadézcame usted -añadió [...]-; yo también lo compadezco» (1998: 100). Esta tesis sobre el enclaustramiento social más allá de las rejas institucionales será desarrollada en El apando (1969), como se abordará en el siguiente apartado.

Sin embargo, aunado al fenómeno de la animalización, Revueltas aborda en su narrativa algunos de los mecanismos mediante los cuales el Estado logra tal deshumanización. Su proyecto de novela titulado «El tiempo y el número» (1967) es un buen ejemplo de lo anterior, pues su título justo alude a la sentencia de los presos y al número por medio del cual se les nomina, de tal manera que en el sistema carcelario la distinción entre una y otra persona pasa a ser aquella individualización cuantitativa. Como Revueltas explicó en una conferencia en 1975, él mismo llegó a experimentar la efectividad de tal mecanismo ya que, tiempo después de salir de la cárcel, un antiguo preso le gritó en la calle «iEse 13-74!» y él volteó de inmediato: «Ya no era yo Revueltas, era el '13-74' y además obedecía a esa incitación» (1978A: 324). De manera similar, en su novela Los motivos de Caín (1958), la guerra es descrita como «un cataclismo anónimo y sin culpa» dado que una unidad («F-31») podía disparar «en abstracto contra una posición abstracta» (el punto «X-25») (1975C: 108). Una reducción de las personas a lo numérico que, como señala Revueltas, pone de manifiesto un fenómeno más profundo, a saber, la subversión del conocimiento aritmético, mismo 
que, siendo una conquista del pensamiento humano, deviene en un instrumento para el ejercicio del poder del Estado (cf. 1986: 36).

Es en aquel proyecto de novela, empero, donde Revueltas expone una vía de liberación alternativa a la muerte. Así, uno de los personajes encuentra una manera de negar su reclusión en el complejo penitenciario de las Islas Marías por medio de lo que la persona narradora describe como «una especie de entretenimiento salvaje, primitivo y alucinante, que [era] correr en una plataforma de roca [...] hasta el borde del abismo y regresar antes de que el mar [pudiera] llevárselo» (Sáinz, Poniatowska, et al., 2001: 108). La libertad de tal personaje descansa, por lo tanto, en su asunción de la posibilidad de su muerte por medio de un ejercicio que, durante algunos segundos, le permite negar la negación que de hecho constituye el tiempo al que está sentenciado.

En cambio, el intento fallido de suicidio de Prudencio, uno de los presos comunistas en Los muros de agua, muestra las implicaciones de semejante escapatoria fallida. Al no fallecer sino sólo perder la razón tras un golpe en la cabeza, Prudencio queda confinado a lo efímero de un instante, incapaz de comprender el presente y, por lo tanto, incapaz de acudir al pasado o recordar, lo mismo que proyectar al futuro o «aguardar la alegría» como el resto de sus camaradas: «Se vivía nada más el instante preciso, sin memoria y sin capacidad de porvenir» (1941: 102). En otras palabras, lo que consigue Prudencio, siguiendo una expresión que emplea Revueltas en sus notas para «El tiempo y el número», no es «la desenajenación suprema, [...] [la libertad] en la nada» que se consigue con la muerte (1981: 311-312), sino un encierro en sí mismo, sin conciencia ya siquiera del propio sufrimiento.

De manera similar, en Los días terrenales se narra cómo Gregorio es aprehendido y, tras ser abandonado por el PCM, queda recluido en un espacio oscuro en el cual el tiempo «simplemente no existía» (1992: 159). Como apuntan Dario Melossi y Massimo Pavarini, el confinamiento solitario es un método mediante el cual se reduce al prisionero al nivel de un «sujeto abstracto» (Melossi y Pavarini, 1981: 162). La efectividad de esta violencia, por lo tanto, estriba en el encierro de la persona en un espacio en el que no solamente se le aísla de cualquier contacto con el exterior y otras personas, sino que además se le impide la mera delimitación del espacio en el que está encerrada e incluso se le oculta su ubicación, propiciando un enclaustramiento en su propia conciencia. De ahí el intento de Gregorio por medir la celda en la que se encuentra, durante lo cual se topa con «un objeto inesperado» (un «W.C.») que la persona narradora describe como «casi el segundo yo», pues de cierta manera posibilita en Gregorio su ‘conciencia del yo’ (1992: 160).

Como lo muestran tanto el caso de Gregorio como el de Prudencio, Revueltas además pone de manifiesto con su encierro el hecho de que, al actuar en contra del sistema gubernamental con el fin de deponerlo, los comunistas sufrían 
un mayor ejercicio de la legalidad que los 'auténticos' criminales. Así, en Los errores (1964) se insiste en que, como sugiere Javier Durán, la cárcel aparece para aquellos «como una referencia, como una experiencia necesaria en la lucha revolucionaria» (Durán, 2002: 150); una experiencia, por lo demás, donde las personas «se conoce[n] [...] mutuamente hasta el fondo, [sin] escapatoria» (1979: 70). Incluso, en esta última novela Revueltas llama la atención sobre la represión de la parte crítica de la acrítica organización comunista, la disidencia dentro de la disidencia o los marginados entre los marginados:

¿no era concreta la verdad de las expulsiones, encarcelamientos y asesinatos de comunistas en la URSS? ¿No era una verdad concreta la injusta y estúpida prisión de Emilio Vadilla, en vaya a saberse qué punto ignorado de la Unión Soviética? ¿No era una verdad concreta la de su propia expulsión del partido, sustentada en una mentira no menos concreta? (1979: 197)

En 1943, de hecho, Revueltas fue expulsado del PCM debido a su crítica hacia varios dirigentes de esa organización, distanciándose de las organizaciones políticas y sus actividades durante los años subsecuentes. Sin embargo, en 1956 reingresó al PCM, publicando una «declaración política de reingreso» en la cual, aunque es sumamente crítico con lo que denomina el «centralismo democrático» de dicho partido, defiende que éste continúa siendo el representante al menos teórico de la clase proletaria (1984: 45ss.). Algo sobre lo cual insistió un año después cuando declaró que, para él, si bien el PCM «todavía no [era] un verdadero partido marxista-leninista», éste era «el único partido capaz» de llegar a serlo (1984: 143). Como lo sugiere el fragmento antes citado de su novela de 1964 y como se discutirá en el siguiente apartado, una década más tarde la postura de Revueltas había cambiado, de lo cual podría ser muestra su tratamiento más 'genérico' de la cárcel.

\section{LA CÁRCEL DENTRO Y FUERA DE LA CÁRCEL}

En 1968 Revueltas formó parte del movimiento estudiantil en México, convencido entonces de que los partidos políticos estaban «caducos y obsoletos» (1980B: 29) y de que el primer paso hacia una autogestión social era la promoción de una autogestión académica como «organización de la conciencia» al margen de aquellos (1978C: 107ss.). Para Revueltas, los estudiantes constituían los nuevos representantes de la corriente proletaria mexicana, reprimida e invalidada diez años antes, durante el movimiento ferrocarrilero (cf. 1978C: 21-22).

Debido a su participación en dicho movimiento estudiantil, y tras la 'matanza de Tlatelolco' el 2 de octubre de 1968, Revueltas fue detenido y encarcelado en Lecumberri, una cárcel diseñada siguiendo el modelo del panóptico de Jeremy Bentham (cf. AGN, 1994). Ahí permaneció poco más de dos años y 
medio durante los cuales escribió y publicó El apando, un texto cuya narración se desarrolla mayoritariamente en la cárcel dentro de la cárcel, a saber, el apando o la celda de castigo. Aún más, la propia estructura narrativa del texto actúa como una suerte de encierro, escrito sin puntos y aparte. Al respecto, Revueltas comentó en un seminario en 1975 (seis años después de la publicación de aquella obra y un año antes de morir) que tal característica de enclaustramiento no fue una «idea preconcebida, sino una necesidad del material», pues el texto debía «representar un hermetismo, [...] un espacio cerrado» (Sáinz, Poniatowska, et al., 1977: 39) que le llevara a uno a cuestionar el propio encierro.

Como el propio Revueltas dijo en aquella charla, y como antes se mencionó a propósito de Los muros de agua, para él la institución carcelaria condensaba el movimiento de la sociedad que le había engendrado y constituía, por ende, un símbolo de «la ciudad cárcel, la sociedad cárcel» (Sáinz, Poniatowska, et al., 1977: 37). El título de un texto inédito de Revueltas que, como apunta Edith Negrín, Charles A. Perrone «publicó en un suplemento mexicano» en 1982 (Negrín, 1995: 185), «El mundo es la cárcel», sería precisamente una alusión explícita a dicha concepción revueltiana. Mientras que, por su parte, diversos personajes de Los errores (1964) ejemplificarían tal idea del mundo como una prisión: Olegario, quien es encarcelado y abandonado por el partido; Lucrecia, para quien todas sus vivencias eran «distintas celdas de esa única larga cárcel que era el haber nacido a la vida» (1979: 133) y quien termina presa de Cobián; Elena, quien termina preso en el veliz que Cobián arroja al canal del desagüe; y Cobián, quien tras ser recluido es liberado y nombrado agente del gobierno, quedando así preso del sistema gubernamental.

Ahora bien, en El apando, como en otros de los textos revueltianos, se muestra la reproducción de la organización jerárquica social dentro de la cárcel, pero a la vez se deja al descubierto el enclaustramiento de todos los habitantes de esta última, tanto celadores como presos. Así, la narración comienza con la descripción de cómo los propios celadores, «hechos para vigilar, espiar y mirar», «cubiertos de ojos de la cabeza a los pies», son vigilados por el ojo derecho de uno de los presos, Polonio, estando como consecuencia «más presos» que éste (1975B: 13-14). La persona narradora pone así énfasis no sólo en una inversión de la vigilancia que va en contra de la disposición institucional, sino, ante todo, en la diferencia entre el saberse encerrados y vigilados de los presos y la ignorancia de los vigilantes sobre la vigilancia y el encierro ejercidos sobre ellos.

Sin embargo, la ausencia de una conciencia real por parte de los presos deriva en que los cuestionamientos sean competencia exclusiva de la persona narradora. Es ésta quien, por ejemplo, constantemente reflexiona acerca de la animalización tanto de los celadores como de los presos, a quienes se refiere con el apelativo de 'monos'; una «implicación zoológica» que, como indicaría Revueltas en el seminario antes mencionado, si bien era común entre los propios 
vigilantes, le «llevó a ver la sociedad como zoología, a través del Estado» (Sáinz, Poniatowska, et al., 1977: 40). De ahí su descripción de la familia de cada uno de los vigilantes como «la familia de monos», pero también la alusión a los «aullidos de perro» del preso apodado El Carajo («él también otro mono»), al ojo de éste «como el de un ave», a su madre como un «animal desconocido» o «una mole de piedra», a los espermatozoides «también monos» y al «avispeo sordo» de la masa de reclusos (1975B: 11, 14, 18, 20, 19, 47, 21 y 48).

Para Revueltas, de hecho, la animalización de todos y cada uno de los personajes en El apando patentiza la enajenación de la racionalidad humana y, con ello, además, la pérdida de la memoria como conciencia histórica-social. A ese fenómeno parece aludir la persona narradora cuando, a propósito de la ignorancia de un 'mono' sobre su encierro, apunta que con éste estaban presos su pareja, sus padres y sus hijos, así como cuando ella se refiere al rostro de los 'monos' como «la forma de cierta nostalgia imprecisa acerca de otras facultades imposibles de ejercer por ellos, cierto tartamudeo del alma [de los monos], en el fondo más bien tristes por una pérdida irreparable e ignorada» (1975B: 13-14). Pero, sobre todo, es el párrafo inicial el que parece dar cuenta de dicho fenómeno:

Estaban presos ahí los monos, nada menos que ellos, mona y mono; bien, mono y mono, los dos, en su jaula, todavía sin desesperación, sin desesperarse del todo, con sus pasos de extremo a extremo, detenidos pero en movimiento, atrapados por la escala zoológica como si alguien, los demás, la humanidad, impiadosamente ya no quisiera ocuparse de su asunto, de ese asunto de ser monos, del que por otra parte ellos tampoco querían enterarse, monos al fin, o no sabían ni querían, presos en cualquier sentido que se los mirara, enjaulados dentro del cajón de altas rejas de dos pisos, dentro del traje azul de paño y la escarapela brillante encima de la cabeza, dentro de su ir y venir sin amaestramiento, natural, sin embargo fijo, que no acertaba a dar el paso que pudiera hacerlos salir de la interespecie donde se movían, caminaban, copulaban, crueles y sin memoria, mona y mono dentro del Paraíso, idénticos, de la misma pelambre y del mismo sexo, pero mono y mona, encarcelados, jodidos. (1975B: 11)

Aún más, para Revueltas tal enajenación, tal subversión de la persona, su memoria y sus relaciones cognoscitivas se evidencian en la propia cárcel en tanto, dice, «grado máximo de la enajenación de la conciencia arquitectónica» (1986: 36). Como él mismo indicó, «la 'geometría enajenada' [...] es probablemente el eje metafísico, el eje cognoscitivo de la novela» (Sáinz, Poniatowska, et al., 1977: 43). En efecto, si bien aquella cita es inexacta, dado que la persona narradora más bien habla de la «gigantesca derrota de la libertad a manos de la geometría», el final de El apando pone de manifiesto dicha enajenación del conocimiento al referirse al «diabólico sucederse de mutilaciones del espacio, triángulos, trapecios, paralelas, segmentos oblicuos o perpendiculares, líneas y 
más líneas, rejas y más rejas» (1975B: 54-55), cuando los celadores introducen tubos entre los barrotes de las rejas de una jaula para inmovilizar a los presos involucrados en una revuelta. Como se discutirá en el siguiente apartado, los últimos relatos de Revueltas justamente pasarán a enfocarse en la prisión mental, dejando la prisión física de lado.

\section{LA RECLUSIÓN EN LA CONCIENCIA}

En 1974 Revueltas publica Material de los sueños, una compilación de relatos escritos entre principios de la década de 1960 y principios de la década de 1970. Mientras que en la mayor parte de sus otros textos narrativos las coordenadas espacio-temporales están claramente definidas, en varios de aquellos relatos los indicios contextuales apenas dan pauta para decir algo acerca del espacio narrativo. En particular, ello ocurre así en «El reojo del yo» (1969), el cual parecería formar parte de un proyecto conformado por parábolas con tintes oníricos basadas en los signos zodiacales y al que pertenecerían, además, «Virgo» (originalmente «Parábolas improbables: virgo»), «El sino del escorpión» (en el borrador «Scorpio. Parábola de los escorpiones») y «La multiplicación de los peces» (en el borrador «Piscis. Parábola de la multiplicación de los peces» (1998B: 133). ${ }^{2}$

Sin embargo, pese a los vínculos entre «El reojo del yo» y aquellos otros relatos de la serie, aquel no sólo explora directamente el encierro en la conciencia, sino que lo hace por medio de características sui generis en la narrativa revueltiana. Así, dicho relato está narrado en primera persona, por lo que el acto de traer al lenguaje la historia y la destinación, o la función de dirigir la historia, no procede de la persona narradora como ocurre en el relato canónico (cf. Filinich, 1999: 114), sino que recae en la voz del personaje principal, a saber, Yo. Aún más, Yo discurre principalmente en tiempo presente, de tal manera que el relato constituye ante todo el registro, y el registro escrito dado que se trata de un «[d]iario» (1998B: 111), de lo que está pensando y sintiendo, así como de lo que tanto Yo como Él, el otro personaje, están haciendo.

Por su parte, si bien en «El reojo del yo» no se sabe nada concreto sobre el espacio en el que se encuentran ambos personajes, este es señalado en general mediante expresiones que denotan aflicción (por ejemplo, «lo que más odio de todo cuanto aquí padezco») y encierro (por ejemplo, «atados a nuestro círculo» o «[e]sta situación de recelo y vigilancia») (1998B: 112). Precisamente, como lo muestran dichas expresiones, a lo sumo el espacio narrativo es «deictizado»

2 «El reojo del yo» se publicó originalmente en febrero de 1969. Una nota incluida en su Diario de Lecumberri, misma que constituye el primer párrafo de aquel relato, sugiere que Revueltas lo redactó entre diciembre de 1968 y principios de enero de 1969 (cf. 1987: 172; 1998B: 134). 
(cf. Greimas, 1980) por índices que no sólo apuntan una ubicación común («estamos en esta pequeña isla»), sino además una distancia entre el aquí de Yo y el allá de Él, como sucede cuando el primero escribe: «Capto [...] ese momento críptico y desasosegante en que Él [...] se dispone a tomar asiento en el retrete» (1998B: 110-111).

Ahora bien, cuando Yo se refiere a su ubicación presente como una «pequeña isla» no la hace en un sentido literal, sino que alude al concepto hermético de Dios retomado durante el Renacimiento por Nicolás de Cusa y Giordano Bruno. Según tales autores, el universo, en tanto efecto procedente del Infinito, sería a su vez esférico e infinito y el ser humano, en tanto manifestación de aquél y debido a su intelecto, podría ser considerado un pequeño universo o «microcosmos» (cf. Cusa, 1981; Yates, 1983): «Bien, estamos en esta pequeña isla que tiene su centro en todos los puntos y su circunferencia en ninguno, de acuerdo con la antigua y sabia definición de viejos pensadores ya no discernibles en la Historia» (1998B: 109), escribe Yo al inicio de su diario. El hecho de que posteriormente Yo evoque al dios Hermes (cf. 1998B: 114) justo refuerza la interpretación de que la falta de indicios que permitan datar su escritura -e incluso decir algo sobre su ubicación futura o pasada- está vinculada a su consideración como un pequeño mundo.

Aún más, como lo sugieren frases como «viejos pensadores ya no discernibles en la Historia» y «una Época, cuyas datas se han escapado para siempre», en el relato existe un movimiento de desaparición del recuerdo semejante al que se encuentra en otros dos de los relatos que conforman Material de los sueños. En «Hegel y yo...» (1973), un relato que formaba parte de un proyecto de novela que pretendía cuestionar el problema de «un solo gran Estado universal» (Sáinz, Poniatowska, et al., 1977: 11), el personaje-narrador atribuye a su compañero de celda, apodado Hegel, la idea de que «la memoria no es lo que se recuerda, sino lo que olvidamos», o dicho de otra manera, «la memoria es lo que uno hace y nadie ha visto, lo que no tiene recuerdo» (1998B: 13). Como explicó Revueltas en una entrevista de alrededor de 1975, tales líneas hacían referencia a «una especie de memoria inarticulada, irracionalizada, que se registra en la clave genética de [los seres humanos]» (Sáinz, Poniatowska, et al., 2001: 161), esto es, una suerte de memoria profunda más allá de los recuerdos.

De manera similar, en «Ezequiel o la matanza de los inocentes» (1969), una alegoría de la 'matanza de Tlatelolco' a través de las visiones que Ezequiel tiene sobre la caída de Jerusalén desde lo alto de una torre panóptica, la persona narradora describe cómo las cosas alrededor de aquél «se le daban [...] desnudas de toda significación, en su naturaleza concreta y pura» o en su «concreto estar allí», despojadas, como la memoria, «de todas las mediaciones que las encubrieran a lo largo del tiempo y de la historia» (1998B: 118-119). De ahí que Ezequiel, inmerso en ese «proceso del recuerdo en que éste se desdoblaba [...] 
hasta convertirse en la acción absoluta de recordar, desprovista ya de la cosa recordada», llegue incluso a identificarse con lo inerte: «soy la silla muerta, soy la mesa muerta, soy la ventana muerta» (1998B: 119-120).

Como Revueltas indicó en un apunte manuscrito, el relato «Ezequiel» tendría que ver con lo que él denominó una «[t]eoría del también de los otros y de las cosas, el también otro del yo, la otredad del también y del otro de la cosa y de la cosa y el yo» (1998B: 134). Esto coincidiría, primero, con la propia nominación de los personajes en «El reojo del yo», Yo y Él, así como con el empleo tanto de fórmulas que reafirman la identidad de cada uno de ellos a lo largo del relato (por ejemplo, «Él a su círculo y Yo al mío» o «Él de la Suya y Yo de la Mía»), como de fórmulas que enfatizan la alteridad (por ejemplo, «mirándonos cada Uno con los ojos del Otro» 0 «Él el primero y Yo el segundo; Yo el primero y Él el segundo») (1998B: 109-110). Pero, además, aquello coincidiría con la propuesta dialéctica que Revueltas planteó en el prólogo a la segunda edición de Los muros de agua (1961) como intención narrativa y que desarrolló teóricamente en sus Apuntes para un ensayo sobre la dialéctica de la conciencia ${ }^{3}$ un texto que Revueltas comenzó a escribir alrededor de 1970. Como apunta Henri Lefebvre, la relevancia de tal propuesta justamente radica en que en ella «el fundamento de la dialéctica se descubre en el sujeto», el cual «entra en contradicción consigo mismo» dada la «relación conflictual [esencial] entre el Mismo y el Otro» (1986: 14).

En «El reojo del yo», empero, la relación conflictual entre Yo y Él resulta sumamente peculiar, dado que, si bien el espacio en el que se encuentran es apenas descrito metafóricamente como una isla, la idea de aislamiento implícita en ésta y la analogía entre aquélla y el «círculo» al que están «atados» (cf. 1998B: 109) sugieren una suerte de encierro. De hecho, el que los únicos objetos sensibles que la narración sitúa en dicho espacio sean un retrete y el «tirso que otrora rob[ó] [Yo] a la estatua del dios Hermes» (usado como desatascador) (1998B: 114), dejando de lado su diario y el instrumento empleado para escribir en éste, ambos objetos no verbalizados, refuerza la tesis del encierro: en la adaptación cinematográfica de El apando, cuyo guión fue coescrito por José Revueltas y José Agustín, el único objeto que aparece en la celda de castigo o apando es un improvisado escusado (cf. Lozoya y Cazals, 1975); mientras que, en Los días terrenales, el único objeto en la celda de confinamiento solitario en la cual termina encerrado Gregorio es un «W. C.» (1992: 164). Aún más, el que Yo les describa a Él y a sí mismo como «esclavos», «sin esperanza», «tortura[dos]» y «víctima[s]» (1998B: 109, 110 y 113), e incluso «denunci[e]» la perpetua y

3 La versión definitiva de este trabajo data de 1975, un año antes de la muerte de Revueltas, y fue publicada por primera vez en 1982 . 
mutua vigilancia a la que están «condenados» (1998B: 109 y 113), emparenta su discurso con uno escrito sobre y desde la reclusión.

No obstante, como lo sugiere la metáfora de la isla y lo reafirma el acto de lectura («Él es mi Lector Único y Yo soy su Único Lector [...], sin esperanza alguna del Tercer Adán» (1998B: 110)), pero sobre todo el acto de escritura, el encierro en este relato se da más bien al interior de la persona:

Capto, maligna e intensamente, puesta en juego al máximo imaginable la total capacidad de mi reojo para ver, ese momento críptico y desasosegante en que Él, solemne y concentrado, con ademanes llenos de reposo y sabiduría, se dispone a tomar asiento en el retrete y en seguida defeca, severo y reflexivo, con la misma altivez y el mismo colérico enjutamiento de cejas con que lo habrán hecho los majestuosos Dioses del Olimpo. Me acongoja hasta casi convertirse en delirio, la certeza de que ahora y aquí, en este instante, Él ha terminado de escribir en su Diario un idéntico párrafo, paralelo al que Yo escribo, sin quitar ni añadir una tilde. Y repito: sin quitar ni añadir una tilde, para que Él, de igual modo, repita la frase y tanto Él como Yo dejemos de comprender, al unísono - por lo absurdo de la reiteración-, el sentido que encierra [...]. En lo último que nos quedamos del presente relato, fue en el hecho de comprobar que Él ha descrito a mi persona, cierto que con líneas y trazos de indudable vigor plástico, en los momentos en que Yo defeco. (1998B: 111)

Mientras que al inicio de este fragmento es la voz de Yo la que narra el momento en que Él hace uso del retrete, al final parece ser Él quien, en tanto Yo, da cuenta de tal hecho narrado por Yo, ahora Él. Así, dado que ambos personajes coexisten en una misma persona o isla, su escritura es idéntica y simultánea y su «espionaje» mediante el reojo «no deja de registrar el más pequeño de [sus] actos, aun de aquellos que [cada uno] [comet[e] en sueños» (1998B: 111-112). Más allá de que el «paratexto» (Genette, 1989: 11) de este relato no sólo da cuenta de su escritura en la cárcel (Revueltas anotó al final «Cárcel Preventiva, 31 de enero de 1969» (1998B: 114)), sino también de tal duplicidad (el subtítulo es «Géminis» (1998B: 109)), es esta indistinta alternancia de la voz lo que evidencia tanto su encierro como su carácter dual.

Cabe mencionar que existen casos de fenómenos similares en la obra narrativa de Revueltas. Por ejemplo, en su cuento «El árbol Martínez» (1968), el personaje llamado Amado Martínez narra cómo dona su apellido a un árbol que, dice, de esa manera «se convirtió en mi doble» (1981: 249). Sin embargo, la peculiaridad de «El reojo del yo» radica tanto en el hecho de que el relato versa sobre dicho fenómeno como en el tipo de éste último, a saber, un desdoblamiento interno o de la conciencia, mismo que, siguiendo la tipología propuesta por Juan Bargalló respecto a su construcción, se da «por fisión», puesto que 
de aquella persona que en algún momento fuese una, ahora se presentan dos (Bargalló, 1994: 17).

Habitualmente, como señala Víctor Herrera, los modelos de interpretación del doble remiten a planteamientos freudianos, como lo muestra la tendencia a asociar al 'otro' con las pulsiones del Ello (cf. Herrera, 1997: 117). Así ocurre, por ejemplo, en el trabajo de Otto Rank sobre el doble, en el cual éste asocia el desdoblamiento con un narcisismo patológico que origina al otro yo, aquél sobre el cual el yo vierte su amor disfrazado en odio al grado de considerarle una amenaza de la que debe protegerse (cf. Rank, 1971: 69ss.). En cambio, el modelo que Herrera denomina «esquizoide», basado en el trabajo de Ronald David Laing en torno a personas esquizoides y esquizofrénicas, considera «que el origen de estas patologías se encuentra [...] durante la estructuración inicial del sí mismo» (Herrera, 1997: 131-133). Para Laing, en efecto, entre los rasgos de aquellos pacientes están «el divorcio del yo respecto del cuerpo», la división del yo «interior» y la consiguiente pérdida de «su propia identidad e integridad», así como la transformación de la interioridad, de tal modo que «[e]l lugar en que el yo se siente seguro se convierte en una prisión[,] [d] eja inclusive de poseer la seguridad de una celda solitaria [y] [s]u propia morada se convierte en una cámara de tortura» (Laing, 1975: 156-157).

Ahora bien, por una parte, el «modelo esquizoide» no se ajusta del todo a lo que sucede en «El reojo del yo» en la medida en que, como señala Herrera, Laing sitúa el origen de dicha patología «en la más temprana infancia» (Herrera, 1997: 133; cf. Laing, 1975: 37-39), mientras que en el relato de Revueltas no hay indicio alguno que sustente tal interpretación. Antes bien, sus escritos de alrededor de 1970 (por ejemplo, el apunte manuscrito sobre «Ezequiel o la matanza de los inocentes» o sus Apuntes para un ensayo sobre la dialéctica de la conciencia) y sus circunstancias personales al momento de escribir «El reojo del yo» sugieren que, como ocurre con el final de Los días terrenales, lo que Revueltas pretende es mostrar cómo la violencia que el Estado ejerce sobre las personas presas de una u otra manera llega al grado de encerrarlas en sí mismas, produciéndose incluso un desdoblamiento de la conciencia. Además, mientras que para Laing «[e]l yo interior es perseguido dentro de esta cámara por partes concretizadas divididas de sí mismo» (Laing, 1975: 157), en «El reojo del yo» la amenaza del otro estriba en su perpetua vigilancia.

Por otra parte, el modelo propuesto por Rank tampoco se ajusta del todo al desdoblamiento en «El reojo del yo» dado que lo que él pudiera considerar como el amor de Yo por sí mismo no erige a Él como «mensajero de la muerte» (Rank, 1971: 86), sino que, por el contrario, termina por manifestarse sin más, anteponiendo la procreación a la aniquilación: 
De aquí partió la cálida admiración que nos tenemos Uno al Otro, el amor que nos une, la sacrosanta dignidad que nos envuelve, la Piedad y la Misericordia que llenan todos nuestros pensamientos. [...] «Porque estoy solo, siempre he estado solo, y Él no existe ni ha existido jamás», me repito. Me repito me repito me repito me repito...: me procreo. (1998B: 114)

Si bien a lo largo del relato diversas expresiones de Yo muestran que está consciente de la peculiaridad de su relación conflictual con Él, como por ejemplo cuando dice que ambos están atados cada cual a su círculo «que son el mismo» o se refiere al «sádico culparnos Uno al Otro con la masoquista acusación del 'tú fuiste' que sin embargo no llegó a pronunciarse nunca» (1998B: 109 y 114), es sólo al final de su diario cuando, tras negar a su doble, le reconoce, reconociéndose a su vez existente en tanto existe Él.

Finalmente, cabe resaltar que, como en «Ezequiel o la matanza de los inocentes» $\mathrm{y}$ «Hegel y yo», en «El reojo del yo» se plantea la existencia de una memoria sin recuerdos, mismos que se vinculan a la propia escritura. Así, mientras que Yo habla de «una Época cuyas datas se han escapado para siempre» y de «palabras vacías y signalizaciones muertas» (1998B: 110-111), Ezequiel advierte que «en el fondo las palabras no son sino el recuerdo de otras palabras, y esta segunda transposición, o tercera o quinta o milésima, de aquel recuerdo esencial tras del que se anda en busca, no es sino el esconderse del vacío» (1998B: 117-118), y Hegel explica que existen actos profundos inscritos en la «memoria antigua», de los cuales «no hay ninguna data que lo[s] testimonie ni podrá haberla nunca», de ahí que el lenguaje constituya «un rodeo, un extravío pernicioso», pues «quienes lo anotan y lo datan [...] no hacen sino borrar sus huellas y falsificarlo» (1998B: 20-22).

Resulta, pues, interesante que, pese a lo anterior, sea por medio de su discurso escrito que Yo parezca acceder justamente a esa memoria que Revueltas llamó «inarticulada»o «genética» (Sáinz, Poniatowska, et al., 2001: 161), posibilitando el reconocimiento de sí mismo como Él. Como lo explicó poco antes de morir en «Mi posición esencial», una especie de prólogo a su Antología personal, aquella era una cuestión que consideraba vital:

¿Cómo definiríamos lo que podría ser la contingencia diáfana del hombre, en contraposición a la contingencia opaca de toda su historia? Pensemos en el otro de Adán, cuando Adán era el único hombre sobre la superficie de la Tierra, en el Edén. Soñemos en un tiempo por venir en que lo único de la Tierra sea lo humano de la Tierra. El hombre será el otro de Adán, que ya no pensará antropomórficamente puesto que el Otro Adán no es otra cosa que la conciencia racional que existe, y no puede menos que existir, en un número infinito de otros puntos del universo, a más de esta pobre Tierra nuestra. Esa racionalidad que somos nosotros mismos, como la otredad de aquellos que existen en alguna parte. (1975A: 12) 


\section{CONCLusiones}

En una entrevista realizada en 1967, Revueltas señaló que «mi vida literaria nunca se ha separado de mi vida ideológica» y que él partía «de una consideración que no está muy claramente expresada en mi primera obra, pero que la ha informado siempre: el problema de la enajenación del hombre» (Sáinz, Poniatowska, et al., 1977: 88). En efecto, como aquí se ha mostrado, Revueltas examina este problema tanto en su obra narrativa como en sus trabajos teóricos. En particular, Revueltas dedica buena parte de sus trabajos a exponer y analizar la enajenación y las vías de liberación, primero en el marco del sistema penitenciario y, posteriormente, en la ciudad-cárcel y en la conciencia. Como él mismo lo explicó en otra entrevista llevada a cabo en 1968, durante los meses previos al movimiento estudiantil, para él «la primera batalla se da a nivel de la conciencia» (Sáinz, Poniatowska, et al., 1977: 83); algo que, como Edith Negrín apuntó en 1995, no ha sido particularmente estudiado en la narrativa revueltiana (cf. Negrín, 1995: 186).

Precisamente, frente a las diversas maneras de obtener cierta libertad que Revueltas plantea en su narrativa, desde la que esperan conseguir los presos comunistas en Los muros de agua o la que obtiene uno de los personajes en su proyecto de novela «El tiempo y el número» mediante un ejercicio 'suicida', hasta la que creen conseguir los comunistas dogmáticos en Los días terrenales u obtiene Cobián (el delincuente que es nombrado «agente de la reservada») en Los errores, «El reojo del yo» aborda directamente el problema esencial y plantea una posibilidad distinta.

Aunado a ello, empero, aquel relato abre las puertas a una interpretación que transgrede la inmanencia del relato, si se tiene en cuenta que el diario de Yo no sólo constituye su testimonio sino incluso su «denuncia» de «cuanto aquí padezco» (1998B: 112). Más allá de que Yo efectúe tal denuncia en vano al ser Él su único lector posible, cabría la posibilidad de que Yo creyese al menos en la posibilidad de la existencia de otra persona lectora, un «Tercer Adán», siendo ésta aquella que efectivamente lee su diario. Y, por qué no, puesto que «El reojo del yo» fue escrito durante el encierro en Lecumberri de su autor, cabría la posibilidad de que dicho preso desdoblado fuese el propio José Revueltas añorando la existencia de esa otra persona lectora fuera de sí, fuera de la celda, fuera de la cárcel. Después de todo, como él mismo escribió en «Prólogo a mi obra literaria» (1967), «[e]ste escritor que leo es mi propia conciencia de sí desenajenada[,] [s]us palabras son las palabras destinadas por él a pensarme en el instante mismo en que las leo: soy su libertad y él es la mía» (1978A: 131). 


\section{BIBLIOGRAFÍA}

ARCHIVO GENERAL DE LA NACIÓN (AGN) (1994). Lecumberri: un palacio lleno de historia, Secretaría de Gobernación, México.

BARGALLÓ, JUAN (1994). Identidad y alteridad: aproximación al tema del doble, Ediciones Alfar, Sevilla.

BLANCO, JOSÉ JOAQUÍN (1985). «José Revueltas: la soledad habitada», en José Revueltas, CREA / Terra Nova, México, pp. 11-43.

CARR, BARRY (2000). La izquierda mexicana a través del siglo XX, Era, México.

CUSA, NICOLÁS DE (1981). La docta ignorancia, Aguilar, Buenos Aires.

DURÁN, JAVIER (2002). José Revueltas. Una poética de la disidencia, UV, México.

FILINICH, MARÍA ISABEL (1999). La voz y la mirada, Plaza y Valdés / UAP, México.

FOUCAULT, MICHEL (1976). Vigilar y castigar: nacimiento de la prisión, Siglo XXI, México.

GENETTE, GÉRARD (1989). Palimpsestos. La literatura en segundo grado, Taurus, España.

GREIMAS, ALGIRDAS JULIEN (1980). Semiótica y ciencias sociales, Fragua, Madrid.

HERRERA, VÍCTOR (1997). La sombra en el espejo. Un estudio de los mecanismos de desdoblamiento en la edad moderna y en la obra de Jorge Luis Borges, CONACULTA, México.

IRBY, JAMES (1956). La influencia de William Faulkner en cuatro narradores hispanoamericanos, tesis de maestría en Letras Hispánicas, UNAM, México.

LAING, RONALD DAVID (1975). El yo dividido. Un estudio sobre la salud y la enfermedad, FCE, México.

LOZOYA, ROBERTO (productor) y CAZALS, FELIPE (director) (1975). El apando, México, Conacite Uno.

MELOSSI, DARIO Y PAVARINI, MASSIMO (1981). The Prison and the Factory. Origins of the Penitentiary System, The Macmillan Press, UK.

MEYER, LORENZO (1976). «La consolidación de las instituciones», Historia general de México, cuarto tomo, El Colegio de México, México.

NEGRÍN, EDITH (1995). Entre la paradoja y la dialéctica. Una lectura de la narrativa de José Revueltas, UNAM / El Colegio de México, México.

RANK, OTTO (1971). The Double. A Psychoanalytic Study, The University of North Carolina Press, USA.

REVUELTAS, EUGENIA (1985). Vasos comunicantes, UAM, México.

REVUELTAS, JOSÉ (1941). Los muros de agua, $1^{\mathrm{a}}$ edición, México.

, (1975A). Antología personal, FCE, México.

, (1975B). El apando, Era, México. 
_, (1975C). Los motivos de Caín, Organización Editorial Novaro, México.

, (1978A). Cuestionamientos e intenciones, Era, México.

, (1978B). Los muros de agua, Era, México.

, (1978C). México 68: juventud y revolución, Era, México.

, (1979). Los errores, Era, México.

, (1980A). El luto humano, Era, México.

,(1980B). Ensayo sobre un proletariado sin cabeza, prólogo de Andrea Revueltas, Rodrigo Martínez y Philippe Cheron, Era, México.

, (1981). Las cenizas, Era, México.

, (1984). Escritos políticos, primer tomo, Era, México.

, (1986). Dialéctica de la conciencia, prólogo de Henri Lefebvre, Era, México.

, (1987). Las evocaciones requeridas (Memorias, diarios, correspondencia), segundo tomo, Era, México.

, (1992). Los días terrenales, edición crítica, coord. Evodio Escalante, Archivos CSIC, España.

, (1998A). En algún valle de lágrimas, Era, México.

, (1998B). Material de los sueños, Era, México.

RUIZ ABREU, ÁLVARO (1993). José Revueltas: Los muros de la utopía, Cal y Arena, México.

SÁINZ, GUSTAVO, PONIATOWSKA, ELENA, et al. (1977). Conversaciones con José Revueltas, CILL, UV, México.

SÁINZ, GUSTAVO, PONIATOWSKA, ELENA, et al. (2001). Conversaciones con José Revueltas, $2^{\mathrm{a}}$ edición, Era, México.

YATES, F. A. (1983). Giordano Bruno y la tradición hermética, Ariel, Barcelona.

Elías Fuentes Guillén es doctor en lógica y filosofía de la ciencia por la Universidad de Salamanca con Mención de Doctorado Internacional por estudios realizados en el IHPSTUniversité Paris 1. Obtuvo el Premio Extraordinario de Doctorado en filosofía durante el curso 2016/17. Actualmente es investigador postdoctoral en la Facultad de Ciencias de la Universidad Nacional Autónoma de México.

Lineas de investigación

Historia y filosofía de las matemáticas, en particular de las matemáticas Germánicas en los siglos XVIII y XIX. 
Publicaciones recientes

Fuentes Guillén, E., «The notion of natural numbers among Germanic mathematicians during the second half of the 18th century», Revista Brasileira de História da Matemática, Vol. 19, no. 37, 2019 (forthcoming)

E-mail:

eliasfuentesguillen@gmail.com 